\section{Resistance of Tomato Genotypes to Four Isolates of Verticillium dahliae Race 2}

\author{
K.D. Baergen', J.D. Hewitt ${ }^{2}$, and D.A. St. Clair ${ }^{3}$ \\ Department of Vegetable Crops, University of California, Davis, \\ CA 95616-8746
}

Additional index words. Lycopersicon esculentum, verticillium wilt, disease resistance, disease screening

\begin{abstract}
Eight tomato (Lycopersicon esculentum Mill.) genotypes were evaluated based on shoot dry weight for resistance to four isolates of Verticillium dahliae Kleb. race 2 in two greenhouse seedling experiments. The race 2 isolates, obtained from North Carolina, Brazil, and Spain, demonstrated no differences in pathogenicity on the eight lines tested, thus precluding the identification of a third V. dahliae race in this collection. However, highly significant differences in virulence were observed among the isolates. The Brazilian isolate was the most virulent. No tomato genotype showed resistance comparable to that conferred by the single dominant $V e$ gene to $V$. dahliae race 1 . While all tomato lines were susceptible to all race 2 isolates tested, there were significant differences in susceptibility equal to differences in levels of resistance. IRAT L3, Morden Lac, Okitsu Sozai, and 'UC82' significantly outperformed the lowest ranking line XXIV-a. 'Earlypak 7', Morden Mel, and Philippine 2 performance was statistically indistinguishable from that of either the highest- or lowest-ranked lines. Genetic diversity in the host and pathogen and environmental conditions favoring the pathogen likely contributed to the genotype $x$ isolate interactions observed in Expt. 1. These results suggest using diverse isolates when screening for improved race 2 resistance.
\end{abstract}

Tomato verticillium wilt is caused by the fungal pathogen Verticillium dahliae Kleb. Verticillium wilt limited tomato production in many areas before the discovery of genetic resistance. The Ve gene, which confers resistance, was reported in 1951 by Schaible et al. and subsequently was incorporated into most commercial cultivars. As early as 1957, however, $V$. dahliae isolates from California and Canada were discovered that induced typical disease symptoms (chlorosis, stunting, and decreased yield) in cultivars containing the $V e$ gene (Bender and Shoemaker, 1984). Such isolates, designated race 2 for their ability to

Received for publication 18 Aug. 1992. Accepted for publication $26 \mathrm{Feb}$. 1993. This study is a portion of a thesis by K. D. B., submitted in partial fulfillment of MS degree requirements. We are indebted to Nancy Blaker and Paul Morns for their valuable comments. We also thank H. Laterrot and R. Gardner for supplying the isolates and some of the plant material used in this study. This research was supported in part by the California Tomato Research Institute and the California League of Food Processors. The use of trade names in this publication does not imply endorsement of the products named nor criticism of similar ones not mentioned. The cost of publishing this paper was defrayed in part by the payment of page charges. Under postal regulations, this paper therefore must be hereby marked advertisement solely to indicate this fact.

Graduate student. Present address: Citrus Research and Education Center, Univ. of Florida, 700 Experiment Station Rd., Lake Alfred, FL 33850.

${ }^{2}$ Assistant Professor. Present address: Rogers NK Seed Co., P.O. Box 1827, Gilroy, CA 95021.

${ }^{3}$ Assistant Professor to whom reprint requests should be addressed. overcome resistance conferred by the Ve gene, since have been identified around the world (Bender and Shoemaker, 1984), most recently in Australia (O'Brien and Hutton, 1981), Brazil (Laterrot et al., 1983), Morocco (Besri et al., 1984), Florida (Jones and Overman, 1985), South Africa (Ferreira et al., 1990), and Crete (Ligoxigakis and Vakalounakis, 1992). In California, race 2 has reduced tomato yields by as much as $25 \%$ (Grogan et al., 1979). North Carolina race 2 isolates decreased yields $10 \%$ to $30 \%$ (Bender and Shoemaker, 1984). Because of the persistence of Verticillium microsclerotia in the soil, methods other than complete soil sterilization fail to control the pathogen completely (Pegg, 1974; Talboys, 1984). Durable genetic resistance to race 2 , therefore, is particularly desirable as a control method.

Previous researchers, using one or two race 2 isolates, have identified tomato genotypes that demonstrated potentially useful levels of resistance against those particular pathogen isolates (Laterrot, 1984; Okie and Gardner, 1982a, 1982b). In the present study, eight tomato genotypes were evaluated for their resistance to four geographically diverse $V$. dahliae race 2 isolates. The relative virulence of these isolates on the tomato lines also was assessed. Finally, this study considered whether significant genotype $\times$ isolate interactions could be detected in this collection of tomato lines and race 2 isolates.

Six of the tomato genotypes-Morden Mel, Morden Lac, IRAT L3, Okitsu Sozai, Philippine 2, and XXIV-a-were chosen for evaluation based on previous reports of their resistance to $V$. dahliae race 2 (Laterrot, 1984, Okie and Gardner, 1982a, 1982b). Two California cultivars-Earlypak 7, reported to be race 2-susceptible (Grogan et al., 1979), and UC82-were included for comparison. Tomato seeds were sown in steam-pasteurized UC soil mix.(Baker, 1957) in 4-liter pots and grown in a greenhouse in Davis, Calif., to the fully expanded cotyledon stage. Sowing dates were staggered to ensure that all seedlings were at the same morphological stage at inoculation. Chronological age at inoculation ranged from 9 to 12 days after sowing.

Four $V$. dahliae race 2 isolates originating from North Carolina (isolates 2-105 and 2RG; Okie and Gardner, 1982b), Brazil (isolate 2-BRAZIL; Laterrot et al., 1983), and Spain (isolate 2-3-9; Laterrot et al., 1983) were used. Cultures were maintained in the dark on potato dextrose agar slants at 21C. Inoculum was prepared using 3-to 6-week-old cultures. Distilled water was added to each culture tube, which was then vortexed to facilitate spore release. Suspensions from three or more tubes were combined for each isolate, and the resulting slurry was sieved through a double layer of cheesecloth to remove mycelial fragments. Spore concentration was determined using a hemacytometer and adjusted to a final concentration of $1 \times 10^{6}$ spores $/ \mathrm{ml}$. This concentration was sufficient to cause symptoms consistently on the susceptible control, 'Earlypak 7'. Since preliminary experiments indicated that all of the isolates had $>90 \%$ spore germination, adjusting the concentration further was deemed unnecessary. Before inoculation, groups of seedlings were removed from the pots and roots were rinsed free of adhering soil. Roots were trimmed with a razor blade to $0.5 \mathrm{~cm}$ long and suspended in 200 to $250 \mathrm{ml}$ of inoculum for $10 \mathrm{~min}$. Thirty plants each of the eight tomato genotypes were inoculated with one of each of the four isolates or distilled water as a control. Following inoculation, groups of six plants from each treatment were transplanted into five 4-liter pots filled with UC soil mix. Quarantine conditions were maintained during the experiments because isolates foreign to California were used. To prevent the escape of potentially infested soil or water from the pots during the experiment, the pots were contained within seamless, heavy-duty, plastic circular children's wading pools measuring $1.5 \mathrm{~m}$ in diameter. Pots were placed on raised wire mesh platforms $3 \mathrm{~cm}$ high in the pools to prevent possible cross-contamination of isolates. Pots were arranged in a randomized complete-block design with five blocks. Each pool was considered a block for statistical purposes; each contained one pot of each of the possible genotype-isolate combinations and one pot of a distilled-water control per genotype for a total of 40 pots per block. The entire. experiment was conducted twice: once in October (Expt. 1) and again in April (Expt. 2). Plants were maintained in the greenhouse " under natural light. Days ranged from 20 to 27C (but tended to be cooler in Expt. 1 than Expt. 2) and nights ranged from 14 to $18 \mathrm{C}$. Daylengths were 10 to $12 \mathrm{~h}$ for Expt. 1 and 12.5 to $14 \mathrm{~h}$ for Expt. 2. Plants were watered 
daily and fertilized biweekly with a soluble $15 \mathrm{~N}-15 \mathrm{P}-18 \mathrm{~K}$ fertilizer solution (Plantex; Plantco, Ont., Canada). Disease symptoms were evaluated twice weekly. Vascular discoloration in the roots and lower stems was not sufficiently pronounced in our experiments to be used as a criterion. Foliar symptoms were evident and used as an indication of disease. Initially, the criterion was cotyledon wilting and later criteria were wilting of the true leaves and the development of characteristic V-shaped chlorotic areas on the leaf blade as the disease progressed. Experiments ended when the number of new plants developing symptoms declined sharply, a point that generally coincided with the onset of flower bud development ( $\approx 6$ weeks after inoculation). At this point, all plant shoots were harvested by cutting them above the cotyledonary node and evaluated further for disease symptoms.

Disease resistance and isolate virulence wereevaluated based on plant shoot dry weight reduction as a measure of stunting symptoms caused by the pathogen. Shoot dry weights were averaged for each pot. Because of inherent size differences among the tomato genotypes, direct dry-weight comparisons among them were impossible. Stunting, therefore, was computed as relative dry weight (RDW), expressed as a ratio between the average dry weight of isolate-inoculated plants within a pot and the average dry weight of the waterinoculated control plants for that genotype. The calculated RDW values were the standard unit used for subsequent statistical analyses.

RDW values were transformed logarithmically (natural $\log , 1 \mathrm{n}$ ) to equalize variances before analysis of variance, because the variances were proportional to the squares of the treatment means. A mixed-effects model (genotype, isolate, experiment date = fixed; block = random $)($ BMDP Statistical Software, Los Angeles) was used for the analysis to avoid pseudoreplication. Tukey's LSD procedure was used to separate mean RDW values (Steel and Torrie, 1980).

Inoculated plants frequently were stunted and, in extreme cases, plants died. Vascular discoloration generally was not pronounced. Withall genotype-isolate combinations, some plants took several weeks to develop foliar symptoms and some did not develop symptoms at all. All control plants remained symptomless during both experiments, and attempts to isolate the pathogen from randomly selected control plants were negative. Verticillium was reisolated from all symptomatic inoculated plants that were sampled and frequently was found in inoculated, asymptomatic plants as well. In general, more plants displayed more severe symptoms under the cooler conditions of Expt. 1 than Expt. 2.

All four race 2 isolates induced symptoms in all eight tomato genotypes. Because there were no differences in pathogenicity in the genotypes tested, the identification of a third race of $V$. dahliae in this collection of isolates was precluded. Analysis of variance using a mixed-effects model of the transformed RDW values performed on the combined data indicated significant experiment interactions with each of the other main effects, isolate, and tomato genotype (i.e., significant experiment $\mathrm{x}$ isolate, experiment $\mathrm{x}$ genotype, and experiment $\mathrm{x}$ genotype $\mathrm{x}$ isolate interactions; data not shown). Therefore, all subsequent analyses were performed separately for each experiment (Table 1). Significant genotype and isolate main effects were observed in both experiments. A significant genotype $\mathbf{x}$ isolate interaction was observed in Expt. 1, but not in Expt. 2.

While there were no differences in pathogenicity, there were significant differences in virulence among the race 2 isolates we used (Table 2). The least virulent isolates, 2-105 and 2-3-9, caused light stunting on all eight tomato genotypes. 2-RG virulence was intermediate, whereas 2-BRAZIL was highly virulent on most genotypes tested, causing severe stunting and frequently resulting in the death of young plants. The difference in the isolate virulence may be one reason why tomato genotypes that seem disease resistant in one study may perform poorly in another study when different isolates are used-reported host plant resistance is relative to the virulence of the isolates used to test for that resistance.

No tomato genotype demonstrated resistance to any of the race 2 isolates comparable to that conferred by the $V e$ gene against race 1 . Nevertheless, there were detectable differences in susceptibility, as measured by RDW of inoculated genotypes (Tables 3 and 4). We considered the significant differences in susceptibility equivalent to differences in genotype resistance to race 2 isolates. Experiment
2 lacked a significant genotype $\times$ isolate interaction; thus, genotype performance was averaged over all four isolates (Table 4). IRAT L3, Morden Lac, Okitsu Sozai, and 'UC82' significantly outperformed the lowest ranking genotype, XXIV-a. The performance of 'Earlypak 7', Morden Mel, and Philippino 2 was not significantly different from either the highest-ranked genotypes or the lowest-ranked XXIV-a. Overall, the previously reported resistant genotypes did not demonstrate race 2 resistance significantly greater than that of the susceptible California cultivars Earlypak 7 and UC82.

The significant genotype $\times$ isolate interaction observed in Expt. 1 indicated a failure of all tomato genotypes to show the same response pattern to the four race 2 isolates; therefore, it was impossible to designate a most-resistant tomato genotype in this study (Table 3). Only Philippino 2 behaved consistently, performing significantly worse than most other genotypes, regardless of isolate. The ranking of the remaining tomato genotypes depended on the race 2 isolate used. For specific isolates, our results agreed with those of previous researchers. Morden Mel, identified by Okie and Gardner (1982b) as the most resistant genotype in evaluations with North Carolina isolates, performed exceedingly well in our experiments after being inoculated with either of the isolates originating from North Carolina, 2-RG and 2-105. IRAT L3, identified by Laterrot (1984) as moderately resistant to the highly virulent Brazilian isolate, was similarly the best performer with that isolate in

Table 1. Summaries of mixed-effects model analyses of variance (ANOVA) of relative dry weight (RDW $=$ shoot dry weight of inoculated plants compared to distilled-water controls) for eight tomato genotypes inoculated with four isolates of Verticillium duhliae race 2 . $^{2}$

\begin{tabular}{|c|c|c|c|c|c|c|}
\hline \multirow[b]{2}{*}{ Source } & \multicolumn{3}{|c|}{ Expt. 1} & \multicolumn{3}{|c|}{ Expt. 2} \\
\hline & df & MSE & $\mathrm{F}$ & $\mathrm{d} \mathrm{f}$ & MSE & $\mathrm{F}$ \\
\hline$\overline{\text { Mean }}$ & 1 & 55.32 & $19.87 * *$ & 1 & 14.89 & $43.73 * *$ \\
\hline Error $a^{y}$ & 4 & 2.78 & & 4 & 0.34 & \\
\hline Genotype (G) & 7 & 3.55 & $22.88 * * *$ & 7 & 0.52 & $3.67 * *$ \\
\hline Error $b$ & 28 & 0.16 & & 28 & 0.14 & \\
\hline Isolate (I) & 3 & 6.47 & $47.26 * * *$ & 3 & 1.19 & $8.46 * *$ \\
\hline Error c & 12 & 0.14 & & 12 & 0.14 & \\
\hline $\mathrm{G} \times \mathrm{I}$ & 21 & 1.08 & $9.44 * * *$ & 21 & 0.28 & $1.54^{\mathrm{NS}}$ \\
\hline Error $\mathrm{d}$ & 84 & 0.11 & & 84 & 0.18 & \\
\hline
\end{tabular}

${ }^{2}$ ANOVA was performed on logarithmically transformed (ln) RDW values.

${ }^{y}$ Due to using a mixed-effects model, individual errors were computed for individual F tests (e.g., genotype MSE/error $\mathrm{b}=\mathrm{F}$ test for genotype effects).

Ns $* * * * *$ Nonsignificant or significant at $P \leq 0.01$ or 0.001 , respectively.

Table 2. Mean virulence of four isolates of Verticillium dahliae race 2 on eight tomato genotypes. Virulence of each isolate was determined by the reduction in relative dry weight (RDW $=$ shoot dry weight of inoculated plants compared to distilled-water controls) averaged over the eight genotypes to calculate mean RDW per isolate.

\begin{tabular}{|c|c|c|c|c|}
\hline \multirow[b]{2}{*}{ Isolate } & \multicolumn{2}{|c|}{ Expt. 1} & \multicolumn{2}{|c|}{ Expt. 2} \\
\hline & $\ln (\mathrm{RDW})$ & $\begin{array}{l}\text { Mean } \\
\text { RDW }\end{array}$ & $\ln (\mathrm{RDW})^{2}$ & $\begin{array}{l}\text { Mean } \\
\text { RDW }\end{array}$ \\
\hline 2-BRAZIL & -1.163 & 0.313 & $-0.530 \mathrm{a}$ & 0.589 \\
\hline $2-\mathrm{RG}$ & -0.564 & 0.569 & $-0.342 a b$ & 0.710 \\
\hline $2-3-9$ & -0.344 & 0.709 & $-0.212 b$ & 0.809 \\
\hline $2-105$ & -0.281 & 0.755 & $-0.136 \mathrm{~b}$ & 0.873 \\
\hline LSD & $\mathrm{G} \times \mathrm{I}^{\mathrm{y}}$ & & 0.249 & \\
\hline
\end{tabular}

${ }^{2}$ Values followed by the same letter do not differ significantly according to Tukey's LSD at $P \leq 0.05$. Mean separation performed on logarithmically transformed (ln) RDW data.

Significant genotype $(\mathrm{G}) \times$ isolate (I) interaction at $P \leq 0.05$ in analysis of variance precludes mean separation; see Table 3 for isolates and genotypes separately. 
Table 3. Relative dry weight (RDW) of eight tomato genotypes inoculated individually with four isolates of Verticillium dahliae race 2 in Expt. 1.

\begin{tabular}{|c|c|c|c|c|c|}
\hline Genotype & $\ln (\mathrm{RDW})^{y}$ & RDW & Genotype & $\ln (\mathrm{RDW})$ & RDW \\
\hline & \multicolumn{2}{|c|}{ Isolate 2-Brazil } & & \multicolumn{2}{|c|}{ Isolate $2-R G$} \\
\hline IRAT L3 & $-0.226 \mathrm{a}$ & 0.798 & Morden Mel & $-0.036 \mathrm{a}$ & 0.964 \\
\hline Earlypak 7 & $-0.252 \mathrm{a}$ & 0.777 & Earlypak 7 & $-0.368 \mathrm{a}$ & 0.692 \\
\hline UC82 & $-0.538 \mathrm{a}$ & 0.583 & UC82 & $-0.383 \mathrm{a}$ & 0.682 \\
\hline Okitsu Sozai & $-0.549 \mathrm{a}$ & 0.549 & IRAT L3 & $-0.508 a b$ & 0.602 \\
\hline Morden Lac & $-1.072 \mathrm{a}$ & 0.342 & Okitsu Sozai & $-0.530 a b$ & 0.589 \\
\hline Morden Mel & $-1.128 \mathrm{a}$ & 0.324 & Morden Lac & $-0.543 a b$ & 0.581 \\
\hline Philippine 2 & $-2.401 \mathrm{~b}$ & 0.091 & XXIV-a & $-0.978 \mathrm{~b}$ & 0.376 \\
\hline XXIV-a & $-3.088 \mathrm{~b}$ & 0.046 & Philippine 2 & $-1.160 \mathrm{C}$ & 0.313 \\
\hline \multirow[t]{2}{*}{ LSD } & 1.256 & & LSD & 0.522 & \\
\hline & \multicolumn{2}{|c|}{ Isolate 2-3-9 } & & \multicolumn{2}{|c|}{ Isolate 2-105 } \\
\hline UC82 & $0.010 \mathrm{a}$ & 1.010 & Morden Mel & $0.055 \mathrm{a}$ & 1.057 \\
\hline Earlypak7 & $-0.215 \mathrm{a}$ & 0.807 & Morden Lac & $-0.073 \mathrm{a}$ & 0.930 \\
\hline IRAT L3 & $-0.252 a b$ & 0.777 & UC82 & $-0.129 a b$ & 0.878 \\
\hline Morden Lac & $-0.260 a b$ & 0.771 & Okitsu Sozai & $-0.143 a b$ & 0.867 \\
\hline XXIV-a & $-0.344 a b c$ & 0.709 & Earlypak 7 & $-0.166 \mathrm{ab}$ & 0.847 \\
\hline Okitsu Sozai & $-0.356 a b c$ & 0.701 & IRAT L3 & $-0.421 b c$ & 0.657 \\
\hline Morden Mel & -0.622 be & 0.537 & Phllippino 2 & $-0.589 \mathrm{~cd}$ & 0.555 \\
\hline Philippine 2 & $-0.712 c$ & 0.491 & XXIV-a & $-0.777 \mathrm{~d}$ & 0.460 \\
\hline LSD & 0.407 & & LSD & 0.332 & \\
\hline
\end{tabular}

${ }^{2}$ Genotype performance was assessed by the reduction in RDW (shoot dry weight of inoculated plants compared to that of distilled-water controls).

'Mean separation according to Tukey's LSD at $P \leq 0.05$, performed on logarithmically transformed (in) RDW data.

Table 4. Relative dry weight (RDW) of eight tomato genotypes inoculated individually with four isolates of Verticillium dahliae race 2 in Expt. 2. ${ }^{2}$

\begin{tabular}{lll}
\hline \hline Genotype & $\ln (\text { RDW })^{y}$ & Mean \\
IRAT L3 & $-0.137 \mathrm{a}$ & 0.872 \\
Morden Lac & $-0.206 \mathrm{a}$ & 0.814 \\
Okitsu Sozai & $-0.217 \mathrm{a}$ & 0.805 \\
UC82 & $-0.242 \mathrm{a}$ & 0.785 \\
Earlypak 7 & $-0.280 \mathrm{ab}$ & 0.756 \\
Morden Mel & $-0.307 \mathrm{ab}$ & 0.736 \\
Philippine 2 & $-0.399 \mathrm{ab}$ & 0.671 \\
XXIV-a & $-0.653 \mathrm{~b}$ & 0.520 \\
LSD & 0.387 & \\
\hline
\end{tabular}

${ }^{2}$ Performance of genotypes was assessed by the reduction in RDW (shoot dry weight of inoculated plants compared to distilled-water controls) averaged over the four race 2 isolates to calculate mean RDW per genotype.

'Values followed by the same letter do not differ significantly according to Tukey's LSD at $P \leq 0.05$. Mean separation performed on logarithmically transformed (in) RDW data.

our evaluations. However, these tomato genotypes did not perform as well when inoculated with the other isolates (Table 3). Differences among genotypes in their response to various race 2 isolates were also observed by Rouamba et al. (1988). However, they evaluated resistance based on the intensity of vascular discoloration of race 2-inoculated tomato genotypes; under the conditions of our study, vascular browning in the roots and lower stems was not sufficiently pronounced to be a useful disease evaluation criterion.

The lower temperatures and shorter daylength of Expt. 1, which favored the pathogen, possibly were responsible for intensifying disease symptoms to the point that differences particular to specific genotype $\times$ isolate combinations became detectable. In a study preliminary to their extensive screen for race 2 resistance, Okie and Gardner (1982b) did not detect a significant genotype $\mathrm{x}$ isolate interac- tion when they evaluated 12 tomato lines inoculated individually with seven $V$. dahliae race 2 isolates from North Carolina. Significant genotype $\times$ isolate interactions would be unlikely in evaluations in which the host genotypes were genetically related, a situation that is possible in breeding programs, or when isolates were genetically related, a situation that is possible when using isolates obtained from the same geographic area. However, when diverse host genotypes are infected by isolates diverse in origin, significant interactions, such as those detected in our experiments, might be encountered. One implication of the significant genotype $\times$ isolate interaction is that tomato genotypes screened to perform well against a particular isolate or group of isolates may perform poorly if grown in art environment containing isolates genetically dissimilar to those in the original screen. Based on our data, we suggest using diverse isolates when screening and breeding for improved race 2 resistance.

We originally chose dry weight as an objective measurement reflecting the potential for host plant damage that might result in yield loss. Grogan et al. (1979) used tomato plant dry weight to evaluate the virulence of $V$. dahliae isolates. On preliminary experiments indicated that, by measuring dry weight reduction, we would be able to distinguish between resistance and susceptibility, as imparted by the presence or absence of the $V e$ gene against race 1 (data not shown). In retrospect, however, this criterion may not have been sensitive enough to distinguish among different levels nor to distinguish discrete categories of host plant susceptibility to race 2 . Differences in RDW of $40 \%$ or more were sometimes statistically indistinguishable in these experiments (Table 3), perhaps due to environmental variation and random experimental error. For example, visual inspection of the plant symptoms indicated that IRAT L3 was more resistant to the highly virulent 2BRAZIL isolate than Morden Lac, but mean separation of the dry weight values failed to detect a significant difference (Table 3 ).

Stunting must be considered in the plant evaluation, however, because foliar symptoms do not always correlate with dry weight reduction. Foliar evaluation alone would have suggested that Philippine 2 was more resistant than the other seven genotypes because of the very subtle foliar symptoms exhibited (only slight wilting and necrosis, and failure to develop the typical V-shaped chlorotic patterns on leaves); but, in terms of dry weight reduction, its performance was consistently significantly worse than almost every other genotype in our experiments. Okie and Gardner (1982b) reported a similar reaction with Ottawa 112 , which never developed chlorotic symptoms when inoculated with race 2 , yet performed poorly in terms of wilting and necrosis. An evaluation that considers foliar and stunting symptoms may more accurately indicate potential host-plant resistance, especially since some combinations did not decrease in dry weight, despite foliar symptoms (e.g., 'UC82' with isolate 2-3-9 and Morden Mel with the two North Carolina isolates; Table 3).

Previous efforts by other researchers led to the identification of tomato genotypes that performed well against certain race 2 isolates, but the term resistance has been applied loosely. To date, no high level of resistance analogous to that conferred by the $V e$ gene against race 1 has been discovered for race 2 . The genotypes screened for race 2 resistance did not fall into discrete categories of resistant and susceptible, rather within a continuous range of greater to lesser susceptibility. Some of these "moderately resistant" genotypes may prove useful in breeding programs, especially if high-level resistance remains elusive. In our experiments, however, there was a tendency for genotype performance to be isolate-specific. While greenhouse seedling evaluations for race 1 resistance conferred by the $V e$ gene accurately predict resistance in the field, whether the same holds true for the performance of the genotypes tested against race 2 in these experiments is unknown. Further study is needed to establish whether there is a link between plant stunting by $V$. dahliae race 2 and fruit yield in field trials.

\section{Literature Cited}

Baker, K.F. 1957. The U.C. system for producing healthy container-grown plants. Calif. Agr. Expt. Sta. Manual 23.

Bender, C.G. and P.B. Shoemaker. 1984. Prevalence of verticillium wilt of tomato and virulence of Verticillium dahliae race 1 and race 2 isolates in western North Carolina. Plant Dis. 68:305-309.

Besri, M., M. Zrouri, and I. Beye. 1984. Appartenance raciale et pathogenic comparee de quelques isolats de Verticillium dahliae (Kleb.) obtenus a partir de tomates resistantes au Maroc. Phytopathol. Z. 109:289-294.

Ferreira, J. F., P.C. van der Merwe, and S.P. Naude. 1990. First report of race 2 of Verticillium dahliae on tomatoes in South Africa. Plant Dis. 74:530. 
Grogan, R.G., N. Ioannou, R.W. Schneider, M.A. Sall, and K.A. Kimble. 1979. Verticillium wilt on resistant tomato cultivars in California Virulence of isolates from plants and soil and relationship of inoculum density to disease incidence. Phytopathology 69:1176-1180.

Jones, J.P. and A.J. Overman. 1985. Management of fusarium wilt, fusarium crown rot, verticillium wilt (race 2), southern blight, and root-knot of tomato on fine sandy soils. Proc. Fla. State Hort. Soc. 98:229-231

Laterrot, H. 1984. Specific resistance of Verticilliun dahliae race 2 in tomato. Tomato Genet. Coop. Rpt. 34:10-11.

Laterrot, H., P.C.T. de Melo, and D. Blancard. 1983. Ocorrencia da rata 2 de Verticillium em tomate
(Lycopersicon esculentum Mill.) industrial no estado de Pernambuco, Brasil. Herr. Bras. 1:2225.

Ligoxigakis, E.K. and D.J. Vakalounakis. 1992. Occurrence of race 2 of Verticillium dahliae on tomatoes in Crete. Plant Pathol. 41:774-776.

O'Brien, R.G. and D.G. Hutton. 1981. Identification of race 2 of verticillium wilt in tomatoes in south-east Queensland. Austral. Plant Pathol. 10:56-58.

Okie, W.R. and R.G. Gardner. 1982a, Breeding for resistance to Verticillium dahliae race 2 of tomato in North Carolina. J. Amer. Soc. Hort. Sci. 107:552-555.

Okie, W.R. and R.G. Gardner. 1982b. Screening tomato seedlings for resistance to Verticillium dahliae races 1 and 2. Plant Dis. 66:34-37.

Pegg, G.F. 1974. Verticillium diseases. Rev. Plant Pathol. 53:157-182.

Rouamba, A., H. Laterrot, and A. Moretti. 1988. Interactions between tomato lines and Verticillium strains of pathotype 2. Tomato Genet. Coop. Rpt. 38:42-43.

Schaible, L., O.S. Cannon, and V. Waddoups. 1951. Inheritance of resistance to verticillium wilt in a tomato cross. Phytopathology 41:986-990.

Steel, R.G.D. and J.H. Tome. 1980. Principles and procedures of statistics. 2nd ed. McGraw-Hill, New York.

Talboys, P. W. 1984. Chemical control of verticillium wilts. Phytopathol. Mediterranean 23:163175 